\title{
Individual changes in neurocognitive functioning and health- related quality of life in patients with brain oligometastases treated with stereotactic radiotherapy
}

\author{
Pim B. van der Meer ${ }^{1} \cdot$ Esther J. J. Habets ${ }^{2} \cdot$ Ruud G. Wiggenraad $^{3} \cdot$ Antoinette Verbeek-de Kanter $^{3}$. \\ Geert J. Lycklama à Nijeholt ${ }^{4} \cdot$ Hanneke Zwinkels $^{2} \cdot$ Martin Klein $^{5} \cdot$ Linda Dirven $^{1,2} \cdot$ Martin J. B. Taphoorn $^{1,2}$
}

Received: 31 January 2018 / Accepted: 8 April 2018 / Published online: 16 April 2018

(c) The Author(s) 2018

\begin{abstract}
Background Recently, it has been shown that at group level, patients with limited brain metastases treated with stereotactic radiotherapy (SRT) maintain their pre-treatment levels of neurocognitive functioning (NCF) and health-related quality of life (HRQoL). The aim of this study was to evaluate NCF and HRQoL changes over time at the individual patient level.

Methods NCF (seven domains assessed with a standardized test battery) and HRQoL (eight predetermined scales assessed with the EORTC QLQ-C30 and BN20 questionnaires) were measured prior to SRT and at 3 and/or 6 months follow-up. Changes in NCF and HRQoL were evaluated at (1) a domain/scale level and (2) patient level.

Results A total of 55 patients were examined, of which the majority showed stable NCF 3 months after SRT, on both the domain level (78-100\% of patients) and patient level (67\% of patients). This was different for HRQoL, where deterioration in the different scales was observed in $12-61 \%$ of patients, stable scores in $20-71 \%$, and improvement in 16-40\%, 3 months after SRT. At patient level, most patients (64\%) showed both improvement and deterioration in different HRQoL scales. Results were similar between 3 and 6 months after SRT.

Conclusion In line with results at group level, most brain oligometastases patients with $\geq 6$ months follow-up and treated with SRT maintained their pre-treatment level of NCF during this period. By contrast, changes in HRQoL scores differed considerably at domain and patient level, despite stable HRQoL scores at group level.
\end{abstract}

Keywords Health-related quality of life $\cdot$ Neurocognitive functioning $\cdot$ Brain metastases $\cdot$ Stereotactic radiotherapy

Pim B. van der Meer and Esther J. J. Habets have contributed equally to this work.

Electronic supplementary material The online version of this article (https://doi.org/10.1007/s11060-018-2868-7) contains supplementary material, which is available to authorized users.

Pim B. van der Meer

pbvandermeer@lumc.nl

1 Department of Neurology, Leiden University Medical Center, PO BOX 9600, 2300 RC Leiden, The Netherlands

2 Department of Neurology, Haaglanden Medical Center, The Hague, The Netherlands

3 Department of Radiotherapy, Haaglanden Medical Center, The Hague, The Netherlands

4 Department of Radiology, Haaglanden Medical Center, The Hague, The Netherlands

5 Brain Tumor Center Amsterdam, Amsterdam, The Netherlands

\section{Introduction}

Brain metastases are a common manifestation of systemic cancer, with an estimated $9-45 \%$ of cancer patients developing brain metastases $[1,2]$. The increasing incidence of brain metastases is most likely attributable to an aging population, the availability of improved imaging to detect smaller lesions, and better treatment modalities for systemic cancer which prolong life, thereby increasing the risk of dissemination of the systemic cancer to the brain $[3,4]$. Although a subgroup of patients experiences longer survival [5], brain metastases are still incurable for most patients and the focus of treatment is mainly palliative [6]. Neurocognitive deficits and a reduced health-related quality of life (HRQoL) are often observed in patients with brain metastases and may be caused by the primary tumor, presence of (brain) metastases themselves, anti-tumor treatment, or supportive medication $[4,7-10]$. Although survival is an important treatment 
endpoint for these patients, maintenance or improvement of neurocognitive functioning (NCF) and HRQoL during the course of the disease are at least as important [11, 12].

Whole-brain radiotherapy (WBRT) has been the standard of care in the past decades, but use of stereotactic radiotherapy (SRT) as an addition to, or as an alternative for, WBRT have increased considerably in recent years [13]. The main component of SRT is precise delivery of focal high dose radiation to a discrete target volume in 1-5 sessions, while minimizing irradiation of surrounding normal tissue [8, 14]. This treatment is particularly useful for patients presenting with limited brain metastases [15], which is the largest subgroup of patients, considering that $70 \%$ of the patients have three or fewer metastases [16]. SRT alone is associated with better NCF and HRQoL, while overall survival (OS) is comparable with WBRT alone or a combination of WBRT and SRT $[5,17,18]$. In contrast, SRT alone carries a risk of intracranial recurrences and patients treated with SRT undergo salvage treatment significantly more often compared with patients receiving both WBRT and SRT [19]. These salvage treatments may increase the risk of neurologic deficits and radionecrosis $[4,20]$.

Habets et al. [21] evaluated NCF and HRQoL prospectively in patients treated with SRT alone for 1-3 brain metastases and found that at group level, NCF and HRQoL remained relatively stable during 6 months from initial treatment, with the exception of physical functioning and fatigue, which worsened over time [21]. Although at group level patients maintained their pre-treatment levels of NCF and HRQoL to a large extent, this may not hold true for all individual patients. Since maintaining or improving NCF and HRQoL is important for all patients treated with SRT, we sought to evaluate changes over time in NCF and HRQoL at the individual patient level.

\section{Materials and methods}

\section{Study population}

Patients were eligible if they were $\geq 18$ years; had $\leq 3$ newly diagnosed brain metastases (maximum diameter of $4 \mathrm{~cm}$ ); and were scheduled to undergo SRT, performed on an out-patient base with a dedicated Linac (Novalis; BrainLABAG, Helmstetten, Germany), construction year 2003. Recruitment of patients took place between January 2009 and February 2012. Exclusion criteria were: prior treatment for metastatic brain tumors; insufficient mastery of the Dutch language; and Karnofsky Performance Status (KPS) score $<70$. The medical ethics committee of the institution approved the protocol. All patients provided written informed consent.

\section{Procedures}

The gross tumor volume (GTV) was contoured on a contrastenhanced T1-weighted MRI. Planning target volume (PTV) was created by adding a 2-mm margin by $3 \mathrm{D}$ expansion to the clinical target volume (CTV), which was equal to the GTV. SRT treatment consisted of $21 \mathrm{~Gy}\left(\mathrm{PTV}<8 \mathrm{~cm}^{3}\right)$ or $18 \mathrm{~Gy}$ (PTV 8-13 $\mathrm{cm}^{3}$ ) in a single fraction or $24 \mathrm{~Gy}\left(\mathrm{PTV}>13 \mathrm{~cm}^{3}\right.$ and metastases near the brainstem) in three fractions of $8 \mathrm{~Gy}$.

The baseline evaluation of NCF and HRQoL was conducted in the week preceding SRT. Follow-up assessments took place 3 and 6 months after SRT. Patients' charts were examined to extract sociodemographic data and clinical variables, including primary tumor, treatment status and medication use. At all time points, MRI scans were made and the status of the primary disease and the use of medication were monitored. If patients showed intracranial progression during follow-up and underwent renewed SRT, provided the number of metastases was $\leq 3$, these patients remained in the study. Patients with intracranial progression who transitioned to WBRT were excluded from further assessment. Patients were included in the statistical analysis if they complied for assessment on NCF and/or HRQoL on at least baseline and 3 months, or 3 and 6 months.

\section{Study instruments}

\section{Neurocognitive functioning}

NCF was assessed with a standardized battery of validated neurocognitive tests found to be clinically relevant in brain tumor patients (Supplementary Table 1) [22-29]. Individual test scores were combined in seven neurocognitive domain scores: verbal memory, visual memory, attention, executive functioning, working memory, information processing speed and visuoconstruction. Raw individual test scores were converted into standardized z-scores, by using means and standard deviations of individually matched healthy controls regarding age, gender, and education level, for four different domains (verbal memory, attention, executive functioning and information processing speed) [30-32]. Published norms were used, corrected for age and education, for the three other domains (visual memory, working memory and visuoconstruction) [33, 34]. A change in $z$-score of $\geq 1.5$ standard deviation (SD) was considered to be clinically meaningful, in line with previous research in the same population [21].

\section{Health-related quality of life}

HRQoL was evaluated with two validated self-assessment questionnaires, (1) the for cancer patients developed 30-item generic European Organisation for Research and Treatment 
of Cancer Quality of Life Questionnaire C30 (EORTC QLQC30) and (2) the 20-item brain tumour-specific EORTC QLQ-Brain Cancer Module (QLQ-BN20) [35, 36]. A selection of HRQoL scales has been made, based on previous findings [37], comprising six QLQ-C30 scales (global health status, physical functioning, emotional functioning, role functioning, cognitive functioning, and fatigue) and two BN20 scales (motor dysfunction and communication deficits). Global health status was rated on a 7-point Likert scale, ranging from 'very poor' to 'excellent'; the functioning and symptom scales were rated on a 4-point Likert scale, ranging from 'not at all' to 'very much'. Raw scores were converted linearly into standardized scores ranging from 0 to 100. A higher score on the global health status and the functioning scales indicates better HRQoL, while on symptom-oriented scales a higher score indicates worse HRQoL. Difference or change score $\geq 10$ points on any given scale were considered to be clinically meaningful [38].

\section{Statistical analysis}

To assess changes in HRQoL and NCF, differences in scores over time were calculated on (1) a domain/scale level and (2) patient level. Above described cut-off scores were used to determine an improvement, deterioration or stable score. Changes in scores were calculated for two different time periods: baseline-3 months, and 3-6 months. A cluster analysis, using $\mathrm{R}$, was performed to identify whether specific HRQoL scales clustered.

Statistical analyses were performed using SPSS version 23.0. Statistical significance for intergroup differences were tested using the $\chi^{2}$ test for categorical variables, the Student's t-tests or Mann-Whitney U-test for two-level continuous variables (depending on the distribution of the data), and the Kruskal-Wallis test for continuous variables with more than two levels. Kaplan-Meier curves were used for analyses of OS, and a log rank test to assess differences in survival. A p-value of $<0.05$ was considered statistically significant.

\section{Domain/scale level}

For both time periods (baseline-3 months, and 3-6 months), patients were assigned to one of three categories: (1) deterioration, (2) stable score or (3) improvement, separately for each neurocognitive domain and HRQoL scale. For NCF, improvement and deterioration were defined as an increase or decrease in score $\geq 1.5 \mathrm{SD}$, respectively, and stable score as $<1.5$ SD change. For HRQoL, improvement and deterioration were defined as $\geq 10$ points increase or decrease respectively, and stable score as $<10$ points increase or decrease.

\section{Patient level}

At patient level, patients were categorized into four categories, separately for NCF and HRQoL, applying the same cut-off scores as in the domain/scale level. These four categories were as follows: (1) decline, (2) improvement, (3) both and (4) stable. Decline and improvement were defined as deterioration or increase in $\mathrm{NCF} / \mathrm{HRQoL}$ on at least one domain/scale respectively, while other domains/ scales remained stable. The category 'both' included both a decline and improvement, whereas 'stable' was defined as no detectable change in any neurocognitive domain or HRQoL scale. Moreover, changes in KPS score, SRT dose received (biologically higher [single fraction 21 or $18 \mathrm{~Gy}$ ] versus lower dosis [ $8 \mathrm{~Gy}$ in three fractions]), total tumor volume (as a proxy for GTV), intracranial progression and active systemic disease were assessed for the four categories, separately for the two time periods.

\section{Results}

Fifty-five out of the original 97 (57\%) patients were eligible for analyses, because they had sufficient data. Baseline sociodemographic and clinical characteristics of the study population are summarized in Table 1 . These baseline sociodemographic and clinical characteristics were compared between patients with and without sufficient NCF/HRQoL data. At baseline, patients without sufficient data had more often a lower KPS score (median of 80 [inter quartile range $(\mathrm{IQR})=70-80]$ vs. $80[\mathrm{IQR}=80-90] ; \mathrm{p}=.002)$ and shorter OS (median of 3.8 months [IQR $=1.6-6.4]$ vs. 12.0 months [IQR $=8.2-12.0] ; \mathrm{p}<.001$ ) when compared to patients with NCF/HRQoL data. NCF and HRQoL scores over time in our subpopulation were similar to the results as previously reported in the original study population (data not shown).

\section{Patient characteristics}

The mean age of the 55 included patients was 63 years $(\mathrm{SD}=9)$ and the primary tumor was most frequently located in the lung (49\%). Although the MRI scan showed a fourth metastasis in two patients, these patients received SRT because of the small size $\left(<0.5 \mathrm{~cm}^{3}\right)$ and were therefore also included. The median total tumor volume at baseline was $7.3 \mathrm{~cm}^{3}(\mathrm{IQR}=3.4-12.8)$ and the 1-year survival rate was $48 \%$, with all patients still alive after 3 months and $87 \%$ after 6 months from initial SRT. 
Table 1 Baseline sociodemographic and clinical characteristics of the patient population

\begin{tabular}{|c|c|c|c|}
\hline & Patients with NCF/HRQoL data & Patients without NCF/HRQoL data & Original study population \\
\hline Patients included, no. (\%) & 55 & 42 & 97 \\
\hline Age in years, mean $\pm S D$ & $63 \pm 9$ & $64 \pm 12$ & $63 \pm 11$ \\
\hline \multicolumn{4}{|l|}{ Sex, no. $(\%)$} \\
\hline Male & $25(45 \%)$ & $21(50 \%)$ & $46(47 \%)$ \\
\hline Female & $30(55 \%)$ & $21(50 \%)$ & $51(53 \%)$ \\
\hline Educational level $^{\mathrm{a}}$, median (IQR) & $3(2-4)$ & $2(2-4)$ & $2(2-4)$ \\
\hline \multicolumn{4}{|l|}{ Brain metastases, no. (\%) } \\
\hline 1 & $21(38 \%)$ & $22(52 \%)$ & $43(44 \%)$ \\
\hline 2 & $23(42 \%)$ & $8(19 \%)$ & $31(32 \%)$ \\
\hline 3 & $9(16 \%)$ & $9(21 \%)$ & $18(19 \%)$ \\
\hline 4 & $2(4 \%)$ & $3(7 \%)$ & $5(5 \%)$ \\
\hline \multicolumn{4}{|l|}{ Tumor volume by patient $\left(\mathrm{cm}^{3}\right)$} \\
\hline Median (range)/(IQR) & $7.3(0.12-63.9) /(3.4-12.8)$ & $10.2(0.15-32.0) /(3.6-15.9)$ & $7.8(0.12-63.9) /(3.5-14.2)$ \\
\hline Missing & $1(2 \%)$ & $0(0 \%)$ & $1(1 \%)$ \\
\hline \multicolumn{4}{|l|}{ Primary cancer, no. (\%) } \\
\hline Non-small cell lung & $27(49 \%)$ & $20(49 \%)$ & $48(50 \%)$ \\
\hline Renal cell carcinoma & $11(20 \%)$ & $1(2 \%)$ & $12(13 \%)$ \\
\hline Melanoma & $4(8 \%)$ & $5(12 \%)$ & $9(9 \%)$ \\
\hline Colorectal cancer & $3(5 \%)$ & $6(15 \%)$ & $9(9 \%)$ \\
\hline Breast cancer & $3(5 \%)$ & $5(12 \%)$ & $8(8 \%)$ \\
\hline Other & $7(13 \%)$ & $4(10 \%)$ & $10(10 \%)$ \\
\hline Missing & $0(2 \%)$ & $1(2 \%)$ & $1(1 \%)$ \\
\hline \multicolumn{4}{|l|}{ Active systemic disease, no. (\%) } \\
\hline Yes & $31(56 \%)$ & $21(50 \%)$ & $52(54 \%)$ \\
\hline No & $24(44 \%)$ & $21(50 \%)$ & $45(46 \%)$ \\
\hline \multicolumn{4}{|l|}{ Chemotherapy, no. (\%) } \\
\hline Yes & $6(11 \%)$ & $6(14 \%)$ & $12(12 \%)$ \\
\hline No & $47(85 \%)$ & $33(79 \%)$ & $80(82 \%)$ \\
\hline Missing & $2(4 \%)$ & $3(7 \%)$ & $5(5 \%)$ \\
\hline \multicolumn{4}{|l|}{ Extracranial metastases, no. (\%) } \\
\hline Yes & $29(53 \%)$ & $25(60 \%)$ & $54(56 \%)$ \\
\hline No & $25(45 \%)$ & $16(38 \%)$ & $41(42 \%)$ \\
\hline Missing & $1(2 \%)$ & $1(2 \%)$ & $2(2 \%)$ \\
\hline \multicolumn{4}{|l|}{ Use of corticosteroids, no. (\%) } \\
\hline Yes & $48(87 \%)$ & $37(88 \%)$ & $85(88 \%)$ \\
\hline No & $4(7 \%)$ & $4(10 \%)$ & $8(8 \%)$ \\
\hline Missing & $3(5 \%)$ & $1(2 \%)$ & $4(4 \%)$ \\
\hline \multicolumn{4}{|l|}{ Use of AEDs, no. (\%) } \\
\hline Yes & $12(22 \%)$ & $9(21 \%)$ & $21(22 \%)$ \\
\hline No & $40(73 \%)$ & $32(76 \%)$ & $72(74 \%)$ \\
\hline Missing & $3(5 \%)$ & $1(2 \%)$ & $4(4 \%)$ \\
\hline \multicolumn{4}{|l|}{ KPS } \\
\hline Median (IQR) & $80(80-90)$ & $80(70-80)$ & $80(70-90)$ \\
\hline KPS $\geq 90$, No. $(\%)$ & $25(46 \%)$ & $9(21 \%)$ & $34(35 \%)$ \\
\hline Missing & $1(2 \%)$ & $0(0 \%)$ & $1(1 \%)$ \\
\hline Survival in months, median (IQR) & $12.0(8.2-12.0)$ & $3.8(1.6-6.4)$ & $7.7(3.9-12)$ \\
\hline
\end{tabular}

Due to rounding, not all percentages add up to $100 \%$

${ }^{a}$ Level 1-8, NCF neurocognitive functioning, $H R Q o L$ health-related quality of life, $S D$ standard deviation, $I Q R$ interquartile range, $A E D s$ antiepileptic drugs, KPS Karnofsky performance status 


\section{Compliance}

During follow-up, compliance dropped from $91 \%$ at baseline $(\mathrm{n}=50)$ to $69 \%$ at 3 and $56 \%$ at 6 months for NCF, and from $98 \%$ at baseline $(\mathrm{n}=54)$ to $93 \%$ at 3 and $85 \%$ at 6 months for HRQoL assessments (Supplementary Table 2). Patients had several reasons for non-compliance, such as progression of disease or the assessment being too demanding.

\section{Neurocognitive functioning}

Prior to SRT, half of the patients with neurocognitive data $(25 / 50,50 \%)$ showed impairments in at least one neurocognitive domain, of which verbal memory was most frequently affected $(10 / 33,30 \%)$.

\section{Domain level}

Three months after initial SRT, deterioration in the different neurocognitive domains was observed in 5/7 domains (3-8\% of patients), while in two domains (verbal memory and visual memory) none of the patients showed deterioration (Fig. 1a). A stable score was observed in all domains (78-100\% of patients), most frequently in verbal memory and visual memory. Improvement was found in 4/7 domains (3-17\% of patients) and was most profound for visuoconstruction. Similar results were observed between 3 and 6 months after initial SRT [deterioration in 4/7 domains, $8-20 \%$ of patients; stable score in all domains, $73-100 \%$ of patients; and improvement in 3/7 domains, $4-8 \%$ of patients (Fig. 1b)]. Post-hoc analysis using a less stringent cut-off, a change in z-score of $\geq 1.0 \mathrm{SD}$, revealed similar results (Supplementary Fig. 1a; Supplementary Fig. 1b).

\section{Patient level}

Three months after initial SRT, $14 \%$ of patients showed a decline in NCF, another $14 \%$ an improvement, $6 \%$ both a decline and an improvement, while $67 \%$ had stable NCF (Fig. 1c). The period covering 3-6 months after initial SRT revealed similar results (decline 33\%; improvement $13 \%$; both $4 \%$; and stable $50 \%$ ). When using the $\geq 1.0 \mathrm{SD}$ cut-off, scores differed from the original results, but still most patients remained stable or improved (Supplementary Fig. 1c).

Changes in KPS scores (Supplementary Table 3), SRT dose received, total tumor volume, intracranial progression or active systemic disease in individual patients did not
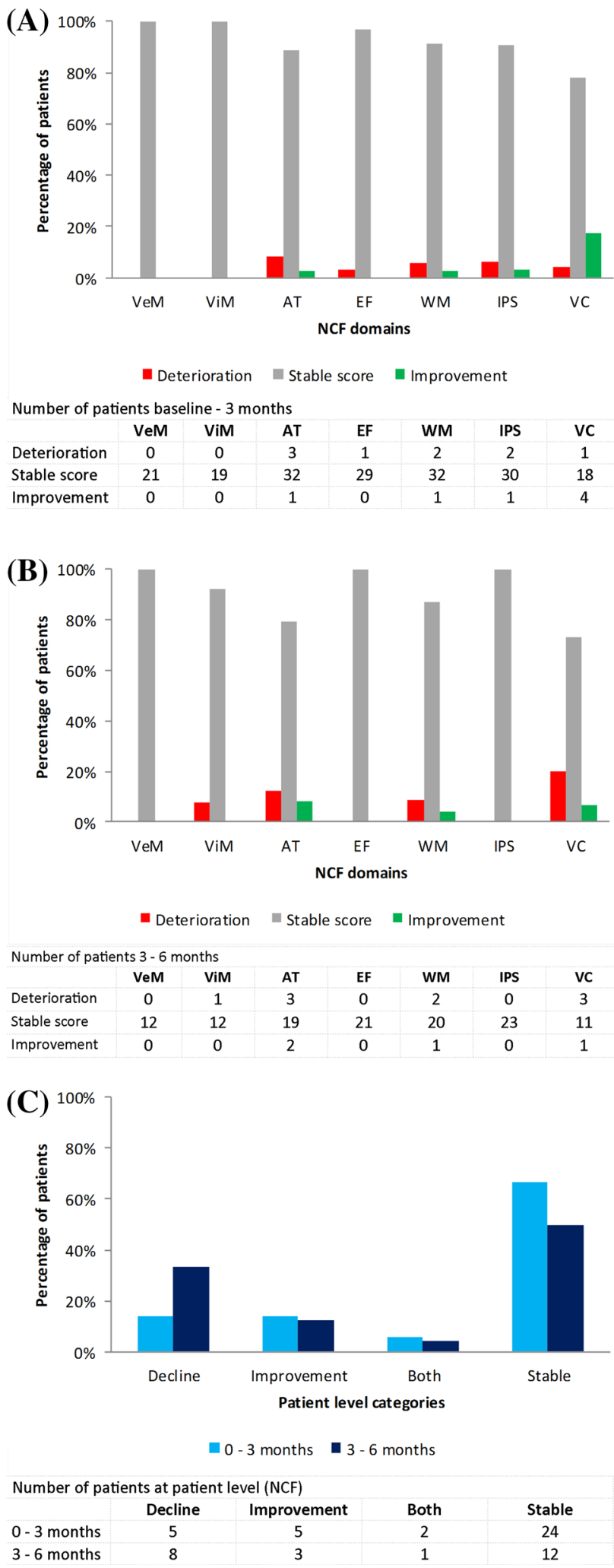

Fig. 1 Changes in neurocognitive functioning (NCF) scores calculated from a baseline-3 months and b 3-6 months at domain level and c patient level. VeM verbal memory; ViM visual memory; $A T$ attention; $E F$ executive functioning; $W M$ working memory; IPS information processing speed; $V C$ visuoconstruction 
differ significantly between the four different categories from baseline to 3 months or from 3 to 6 months after initial SRT.

\section{Health-related quality of life}

Prior to SRT, the vast majority $(48 / 54,89 \%)$ of patients showed a clinically relevant and statistically significant impairment in at least one of the six QLQ-C30 scales when compared to the general population (no reference data available for the QLQ-BN20 scores) [39], of which physical functioning was most frequently affected $(31 / 54,57 \%)$.

\section{Scale level}

Three months after initial SRT, a decline in all eight different HRQoL scales was observed in $12-61 \%$ of patients, most often in fatigue (Fig. 2a). $20-71 \%$ of patients had stable scores and an improvement was shown in $16-40 \%$ of patients most frequently in communication deficit and motor dysfunction respectively. Comparable percentages were found between 3 and 6 months from initial SRT [deterioration $8-47 \%$ of patients; stable score $18-75 \%$ of patients; and improvement $11-34 \%$ of patients (Fig. 2b)].

\section{Patient level}

A decline in HRQoL in the first 3 months was observed in $22 \%$ of patients, an improvement in $12 \%$, both worsening and improvement in $64 \%$, while only $2 \%$ had a stable score (Fig. 2c).

Percentages were comparable 6 months after initial SRT (decline 21\%; improvement 18\%; both 58\%; and stable 3\%). Changes in KPS scores in individual patients differed significantly between the four categories from baseline to 3 months $(\mathrm{p}=.001)$ and from 3 to 6 months $(\mathrm{p}=.036)$ after initial SRT, with patients deteriorating in at least one HRQoL scale (in the 'both' and 'decline' category) showing most often worsening in performance status (Supplementary Table 3). No statistical significant differences between categories were found for SRT dose received, total tumor volume, intracranial progression or active systemic disease (data not shown).

\section{Cluster analysis HRQoL}

A heatmap was created to provide insight into changes in HRQoL at patient level (Fig. 3). The most striking pattern is that fatigue, and to a lesser extent emotional functioning, were clustered with global health status, indicating that a change on one scale is likely to be accompanied by a similar change on the other (i.e. decline, improve, both or remain stable). In addition, physical and role functioning were clustered, as well as several brain tumor-specific symptoms,
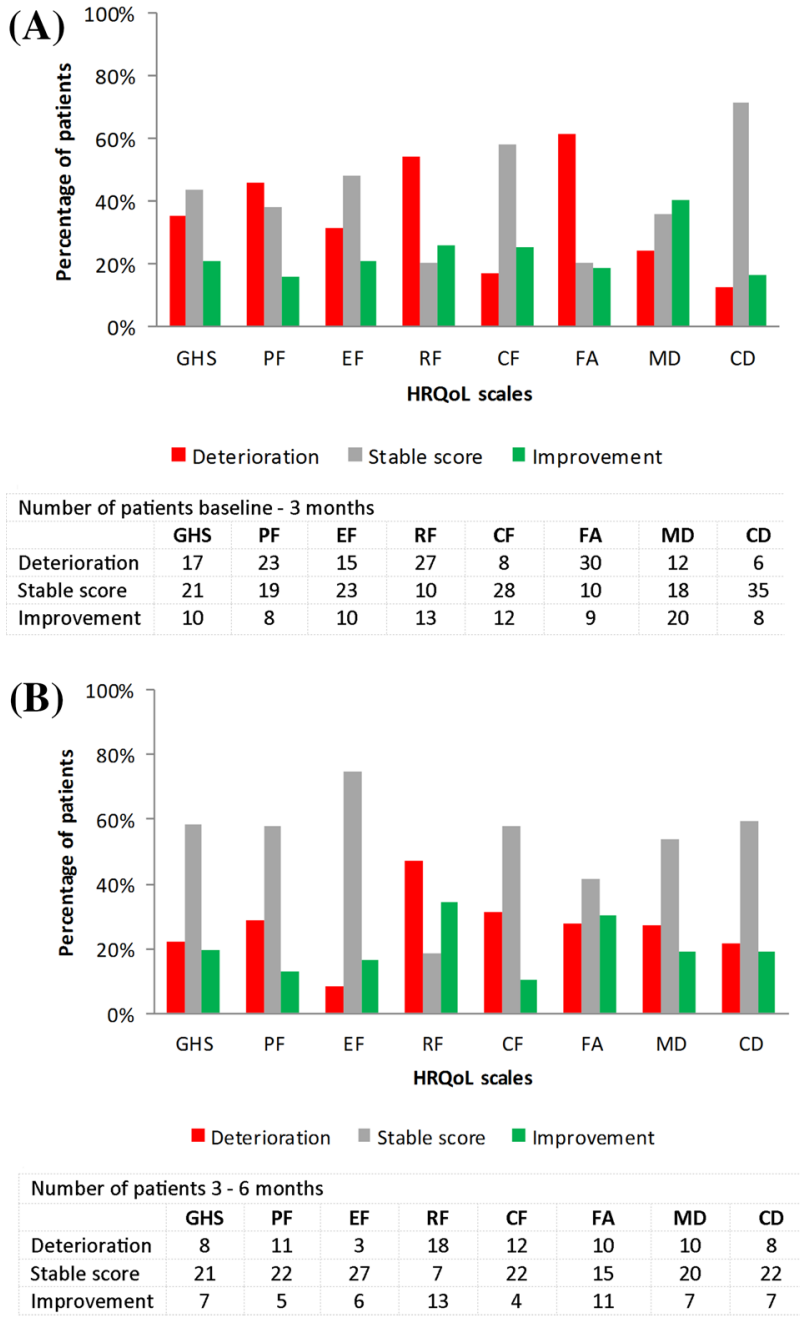

(C)
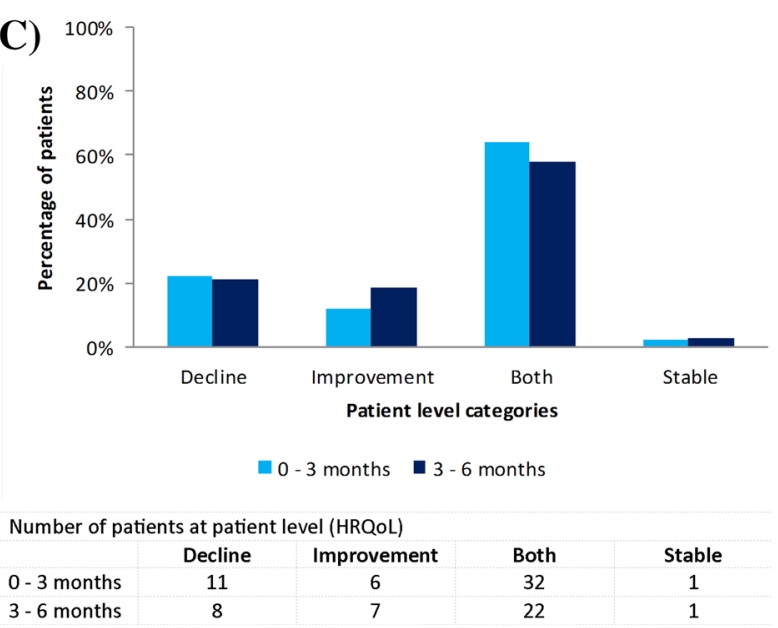

Fig. 2 Changes in health-related quality of life (HRQoL) scores calculated from a baseline-3 months and b 3-6 months at domain level and c patient level. $G H S$ global health status; $P F$ physical functioning; $E F$ emotional functioning; $R F$ role functioning; $C F$ cognitive functioning; $F A$ fatigue; $M D$ motor dysfunction; $C D$ communication deficits 

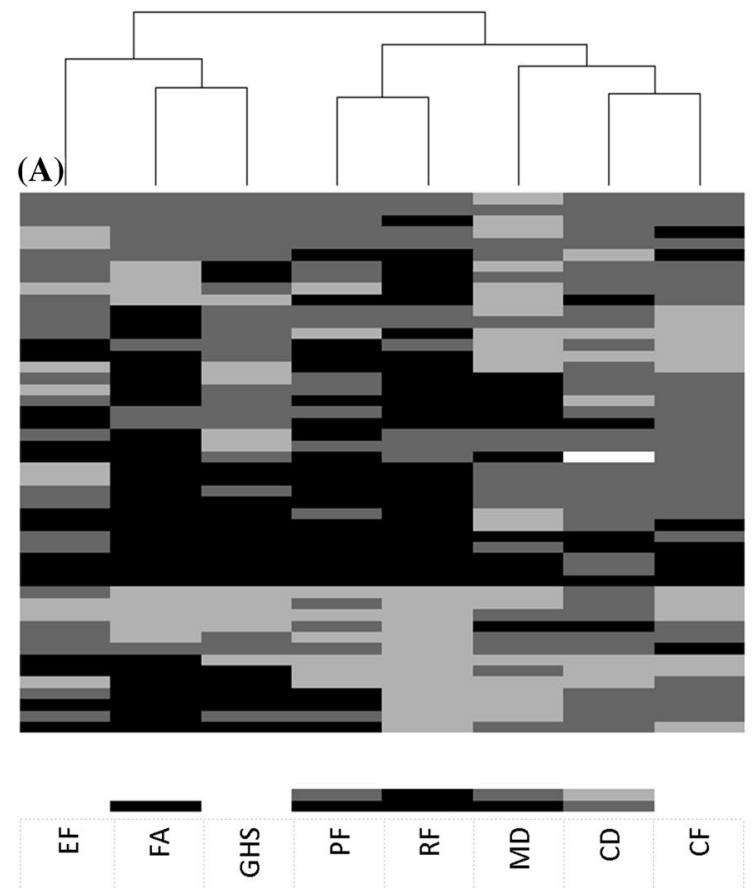

Fig. 3 Cluster analysis of differences in health-related-quality of life scores between a baseline-3 months and b 3-6 months. Black indicates deterioration; dark grey a stable score; light grey improvement; and white a missing value. On the vertical axis all 55 patients included in this study are displayed. a Patients are also clustered, but

these were motor dysfunction, communication deficit and self-perceived cognitive functioning.

\section{Discussion}

The aim of this study was to evaluate changes in NCF and HRQoL at patient level 3 and 6 months after SRT, providing insight in the impact of treatment on the individual patient level. The overall results, in line with results at group level [21] and several other studies in patients with limited brain metastases [19, 40, 41], indicate that most patients with brain metastases treated with SRT maintained their pre-treatment levels of NCF for at least 6 months. Although NCF and HRQoL at the group level showed little variation, this is not necessarily translated into little variation at domain/scale and patient level. Indeed, changes in scores on the different HRQoL scales did vary substantially within patients, and most individual patients showed both a decline and improvement in separate HRQoL scales in the first 6 months after initial SRT. This finding is in contrast with the HRQoL findings at group level, in which patients who deteriorated and improved most likely cancelled each other out. When informing patients about the impact of a certain treatment or monitor their disease status, it is not
(B)

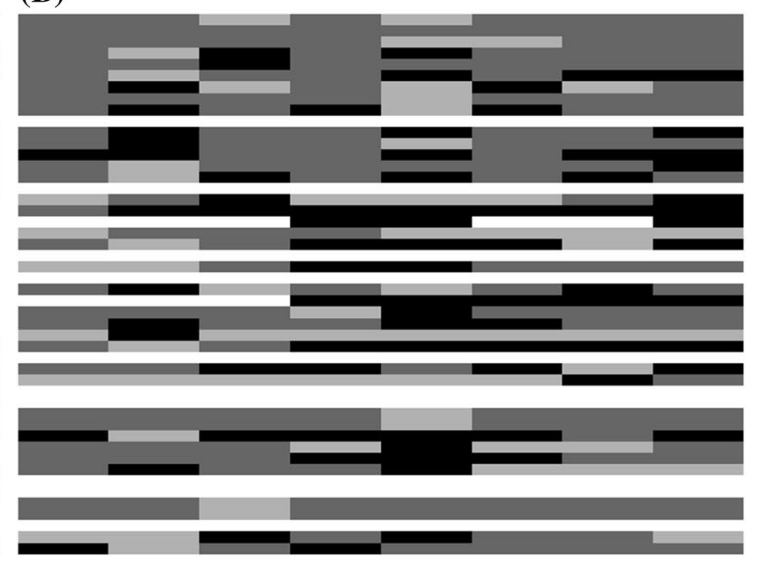

\begin{tabular}{l|l|l|l|l|l|l|l} 
岀 & $\mathbb{1}$ & $\frac{0}{0}$ & 㟔 & 品 & 尺 & 0 & U
\end{tabular}

dendrogram is not shown. b Patients and HRQoL scales are similarly ordered for comparison. $E F$ emotional functioning; $F A$ fatigue; $G H S$ global health status; $P F$ physical functioning; $R F$ role functioning; $M D$ motor dysfunction; $C D$ communication deficits; $C F$ cognitive functioning

sufficient to have information at group level only, nor at the scale level. Clinicians should also be aware that the large majority of patients will experience both deterioration and improvement in HRQoL.

An explanation for the relatively unaffected NCF in brain metastases patients may be that our study population represents a highly selected group of patients with good functioning. Indeed, patients in our sample had a higher KPS score and longer survival compared to our patients without sufficient NCF/HRQoL data. This is also supported by the finding that prior to SRT, only $50 \%$ of patients had an impairment in at least one neurocognitive domain, which is considerably lower than in previous studies in metastatic brain tumor patients (67-92\%) [40, 42]. Particularly for neurocognitive testing, compliance rates decreased substantially over 6 months' time. Responsible for non-compliance, among other things, were poor neurological or physical functioning and assessment considered too burdensome. Another explanation is the operational definition of objective neurocognitive decline, for which different cut-offs have been suggested [43]. Brown et al. [44], using a $\geq 1.0$ SD cutoff score, found considerably higher neurocognitive deterioration rates compared to our study, with most patients showing cognitive deterioration at 3 months after SRT. However, when using a $\geq 1.0$ SD cut-off in our study, still the majority 
of patients showed no cognitive deterioration, meaning a different cut-off does only partially explains the difference in neurocognitive deterioration rates [44]. Taking into account the aforementioned explanations for the relatively unaffected $\mathrm{NCF}$, maintenance of NCF over 6 months' time might have been overestimated in our biased sample and likely limits generalizability of the results to brain metastases patients with poor functioning.

Although average HRQoL remained stable at group level, except for physical functioning and fatigue, this did not hold true on scale level nor at patient level. On scale level, patients were relatively similarly distributed over the three different categories (deterioration; stable score; and improvement). At patient level, however, the majority of patients showed both deterioration and improvement in different HRQoL scales after radiotherapy, which has been previously reported in patients with brain metastases, but comparison is difficult because the majority of patients received WBRT instead of SRT [45, 46]. Caissie et al. [45] reported that upon follow-up 1 month after radiotherapy significant improvement was seen in several HRQoL scales, including communication deficit [45]. On the contrary, Steinmann et al. [46] reported that upon follow-up 3 months after the start of radiotherapy patients showed a significant and clinically relevant deterioration in several preselected HRQoL scales, including global health status, physical functioning, fatigue, motor dysfunction and communication deficit, while other scales remained unchanged [46]. In our study, the majority of patients showed a clinically relevant deterioration between baseline and 3 months in physical functioning $(46 \%)$, role functioning $(54 \%)$ and fatigue $(61 \%)$, reflecting the findings at group level [21]. Nevertheless, considering the varying trajectories of changes in HRQoL after SRT, an important observation is that the majority of our patients showed both decline and improvement in separate HRQoL scales. An explanation for the varying trajectories of changes is that HRQoL measures vastly different concepts, encompassing physical, emotional, and social components, and that this outcome may be influenced by many factors, including comorbidity, marital status, heterogeneity of the primary tumor, SRT dose, total tumor volume, progression of the extracranial cancer and its corresponding supportive or antitumor treatment [47]. Although, SRT dose received, total tumor volume, intracranial progression and active systemic disease did not differ significantly between the four different categories at patient level, this result must be interpreted with caution due to our small sample size. As pointed out by Wilson and Cleary [48] in their model, more distal measures to the disease or the treatment (i.e. global health status and the functioning scales) are not only affected by health status but also by non-medical factors, as opposed to more proximal measures (i.e. symptoms) [48]. NCF is a proximal measure, which is mainly influenced by the presence of brain metastases, or its treatment. Patients who deteriorated on at least one HRQoL scale did most often have decreased performance status, suggesting that especially the patients' overall functioning influences HRQoL. Moreover, Caissie et al. [49] found that fatigue and emotional functioning were the two strongest predictors of global health status in brain metastases patients, which is similar to the findings of our cluster analysis; deterioration in global health status clusters with increased fatigue and worse emotional functioning, suggesting fatigue may be a target for intervention to improve overall HRQoL [49].

To conclude, in accordance with previous results at group level, this study showed that most patients with brain oligometastases treated with SRT maintained their pre-treatment $\mathrm{NCF}$ for at least 6 months. However, changes in scores for the various HRQoL scales differed considerably between and within patients, suggesting that overall functioning is determined by complex underlying mechanisms which should be further analysed.

Funding Funding was provided by St. Jacobusstichting, the Netherlands.

Open Access This article is distributed under the terms of the Creative Commons Attribution 4.0 International License (http://creativeco mmons.org/licenses/by/4.0/), which permits unrestricted use, distribution, and reproduction in any medium, provided you give appropriate credit to the original author(s) and the source, provide a link to the Creative Commons license, and indicate if changes were made.

\section{References}

1. Schouten LJ, Rutten J, Huveneers HAM, Twijnstra A (2002) Incidence of brain metastases in a cohort of patients with carcinoma of the breast, colon, kidney, and lung and melanoma. Cancer 94(10):2698-2705. https://doi.org/10.1002/cncr.10541

2. Barnholtz-Sloan JS, Yu CH, Sloan AE, Vengoechea J, Wang MH, Dignam JJ, Vogelbaum MA, Sperduto PW, Mehta MP, Machtay M, Kattan MW (2012) A nomogram for individualized estimation of survival among patients with brain metastasis. Neuro Oncol 14(7):910-918. https://doi.org/10.1093/neuonc/nos087

3. Nayak L, Lee EQ, Wen PY (2012) Epidemiology of brain metastases. Curr Oncol Rep 14(1):48-54. https://doi.org/10.1007/s1191 2-011-0203-y

4. Soffietti R, Ruda R, Trevisan E (2008) Brain metastases: current management and new developments. Curr Opin Oncol 20(6):676684. https://doi.org/10.1097/CCO.0b013e32831186fe

5. Arvold ND, Lee EQ, Mehta MP, Margolin K, Alexander BM, Lin NU, Anders CK, Soffietti R, Camidge DR, Vogelbaum MA, Dunn IF, Wen PY (2016) Updates in the management of brain metastases. Neuro Oncol 18(8):1043-1065. https://doi.org/10.1093/neuon c/now 127

6. Kamar FG, Posner JB (2010) Brain metastases. Semin Neurol 30(3):217-235. https://doi.org/10.1055/s-0030-1255225

7. Day J, Gillespie DC, Rooney AG, Bulbeck HJ, Zienius K, Boele F, Grant R (2016) Neurocognitive deficits and neurocognitive 
rehabilitation in adult brain tumors. Curr Treat Options Neurol. https://doi.org/10.1007/s11940-016-0406-5

8. Kaal ECA, Niël CGJH., Vecht CJ (2005) Therapeutic management of brain metastasis. Lancet Neurol 4(5):289-298. https:// doi.org/10.1016/s1474-4422(05)70072-7

9. Chang EL, Wefel JS, Hess KR, Allen PK, Lang FF, Kornguth DG, Arbuckle RB, Swint JM, Shiu AS, Maor MH, Meyers CA (2009) Neurocognition in patients with brain metastases treated with radiosurgery or radiosurgery plus whole-brain irradiation: a randomised controlled trial. Lancet Oncol 10(11):1037-1044. https://doi.org/10.1016/s1470-2045(09)70263-3

10. Pectasides D, Pectasides M, Economopoulos T (2006) Brain metastases from epithelial ovarian cancer: a review of the literature. Oncologist 11(3):252-260. https://doi.org/10.1634/theon cologist.11-3-252

11. Dirven L, Reijneveld JC, Taphoorn MJB (2014) Health-related quality of life or quantity of life: a difficult trade-off in primary brain tumors? Semin Oncol 41(4):541-552. https://doi. org/10.1053/j.seminoncol.2014.06.002

12. Schagen SB, Klein M, Reijneveld JC, Brain E, Deprez S, Joly F, Scherwath A, Schrauwen W, Wefel JS (2014) Monitoring and optimising cognitive function in cancer patients: present knowledge and future directions. EJC Suppl 12(1):29-40. https://doi. org/10.1016/j.ejcsup.2014.03.003

13. Muller-Riemenschneider F, Bockelbrink A, Ernst I, Schwarzbach C, Vauth C, von der Schulenburg JM, Willich SN (2009) Stereotactic radiosurgery for the treatment of brain metastases. Radiother Oncol 91(1):67-74. https://doi.org/10.1016/j.radon c.2008.12.001

14. Halasz LM, Rockhill JK (2013) Stereotactic radiosurgery and stereotactic radiotherapy for brain metastases. Surg Neurol Int 4(Suppl 4):S185-S191. https://doi.org/10.4103/2152-7806.11129 5

15. Sahgal A, Aoyama H, Kocher M, Neupane B, Collette S, Tago M, Shaw P, Beyene J, Chang EL (2015) Phase 3 trials of stereotactic radiosurgery with or without whole-brain radiation therapy for 1 to 4 brain metastases: individual patient data meta-analysis. Int $\mathrm{J}$ Radiat Oncol Biol Phys 91(4):710-717. https://doi.org/10.1016/j. ijrobp.2014.10.024

16. Gavrilovic IT, Posner JB (2005) Brain metastases: epidemiology and pathophysiology. J Neurooncol 75(1):5-14. https://doi. org/10.1007/s11060-004-8093-6

17. Soliman H, Das S, Larson DA, Sahgal A (2016) Stereotactic radiosurgery (SRS) in the modern management of patients with brain metastases. Oncotarget 7(11):12318-12330. https://doi. org/10.18632/oncotarget.7131

18. Scoccianti S, Ricardi U (2012) Treatment of brain metastases: review of phase III randomized controlled trials. Radiother Oncol 102(2):168-179. https://doi.org/10.1016/j.radonc.2011.08.041

19. Aoyama H, Shirato H, Tago M, Nakagawa K, Toyoda T, Hatano K, Kenjyo M, Oya N, Hirota S, Shioura H, Kunieda E, Inomata T, Hayakawa K, Katoh N, Kobashi G (2006) Stereotactic radiosurgery plus whole-brain radiation therapy vs stereotactic radiosurgery alone for treatment of brain metastases - a randomized controlled trial. JAMA 295(21):2483-2491. https://doi.org/10.1001/ jama.295.21.2483

20. Regine WF, Huhn JL, Patchell RA, St Clair WH, Strottmann J, Meigooni A, Sanders M, Young AB (2002) Risk of symptomatic brain tumor recurrence and neurologic deficit after radiosurgery alone in patients with newly diagnosed brain metastases: results and implications. Int J Radiat Oncol Biol Phys 52(2):333-338. https://doi.org/10.1016/s0360-3016(01)02645-1

21. Habets EJJ, Dirven L, Wiggenraad RG, Verbeek-de Kanter A, Nijeholt G, Zwinkels H, Klein M, Taphoorn MJB (2016) Neurocognitive functioning and health-related quality of life in patients treated with stereotactic radiotherapy for brain metastases: a prospective study. Neuro Oncol 18(3):435-444. https://doi. org/10.1093/neuonc/nov186

22. Lezak MD, Howieson DB, Loring DW (2004) Neuropsychological assessment. Oxford University Press, New York

23. Tucha O, Smely C, Preier M, Lange KW (2000) Cognitive deficits before treatment among patients with brain tumors. Neurosurgery 47(2):324-333. https://doi.org/10.1097/00006123-20000 8000-00011

24. Saan RJ, Deelman BG (1986) De 15-woordentest A en B (een voorlopige handleiding) [The 15 words test A and B (a preliminary manual)]. Afdeling Neuropsychologie, AZG, Groningen

25. Uterwijk JMR (2000) WAIS-III Nederlandstalige bewerking. Technische handleiding. David Wechsler [WAIS-III Dutch revision. Technical manual. David Wechsler] Wechsler Adult Intelligence Scale III [Dutch revision. Technical manual]. Swets Test Publishers, Lisse

26. Van der Elst W, Van Boxtel MP, Van Breukelen GJ, Jolles J (2006) The concept shifting test: adult normative data. Psychol Assess 18(4):424. https://doi.org/10.1037/1040-3590.18.4.424

27. Krabbendam L, Kalff AC (1998) The behavioural assessment of the dysexecutive syndrome: Dutch version. Swets and Zeitlinger, Lisse

28. Meyers CA, Cantor SB (2003) Neuropsychological assessment and treatment of patients with malignant brain tumors. In: Prigatano GP, Pliskin NH (eds) Clinical neuropsychology and cost outcome research: a beginning. Psychology Press, New York, pp 159-173

29. Osterreith PA (1944) Le test de copie d'une figure complexe [A test regarding a complex figure]. Arch Psychol 30:206-356

30. Jolles J, van Boxtel MP, Ponds RW, Metsemakers JF, Houx PJ (1998) [The Maastricht aging study (MAAS). The longitudinal perspective of cognitive aging]. Tijdschr Gerontol Geriatr 29(3):120-129

31. De Bie SE (1987) Standaardvragen 1987: Voorstellen voor uniformering van vraagstellingen naar achtergrondkenmerken en interviews [Standard questions 1987: proposal for uniformisation of questions regarding background variables and interviews]. Leiden University Press, Leiden

32. Van der Elst W (2006) The neuropsychometrics of aging: normative studies in the Maastricht Aging Study. University of Maastricht, Maastricht

33. Fastenau PS, Denburg NL, Hufford BJ (1999) Adult norms for the Rey-Osterrieth complex figure test and for supplemental recognition and matching trials from the extended complex figure test. Clin Neuropsychol 13(1):30-47. https://doi.org/10.1076/ clin.13.1.30.1976

34. Kessels RP, van den Berg E, Ruis C, Brands AM (2008) The backward span of the Corsi Block-Tapping Task and its association with the WAIS-III Digit Span. Assessment 15(4):426-434. https://doi.org/10.1177/1073191108315611

35. Osoba D, Aaronson NK, Muller M, Sneeuw K, Hsu MA, Yung WKA, Brada M, Newlands E (1996) The development and psychometric validation of a brain cancer quality-of-life questionnaire for use in combination with general cancer-specific questionnaires. Qual Life Res 5(1):139-150. https://doi.org/10.1007/bf004 35979

36. Aaronson NK, Ahmedzai S, Bergman B, Bullinger M, Cull A, Duez NJ, Filiberti A, Flechtner H, Fleishman SB, Dehaes J, Kaasa S, Klee M, Osoba D, Razavi D, Rofe PB, Schraub S, Sneeuw K, Sullivan M, Takeda F (1993) The European Organization for Research and Treatment of Cancer QLQ-C30: a quality-oflife instrument for use in international clinical trials in oncology. J Natl Cancer Inst 85(5):365-376. https://doi.org/10.1093/ jnci/85.5.365 
37. Soffietti R, Kocher M, Abacioglu UM, Villa S, Fauchon F, Baumert BG, Fariselli L, Tzuk-Shina T, Kortmann RD, Carrie C, Ben Hassel M, Kouri M, Valeinis E, van den Berge D, Mueller RP, Tridello G, Collette L, Bottomley A (2013) A European Organisation for Research and Treatment of Cancer phase III trial of adjuvant whole-brain radiotherapy versus observation in patients with one to three brain metastases from solid tumors after surgical resection or radiosurgery: quality-of-life results. J Clin Oncol 31(1):65-72. https://doi.org/10.1200/jco.2011.41.0639

38. Osoba D, Rodrigues G, Myles J, Zee B, Pater J (1998) Interpreting the significance of changes in health-related quality-of-life scores. J Clin Oncol 16(1):139-144

39. van de Poll-Franse LV, Mols F, Gundy CM, Creutzberg CL, Nout RA, Verdonck-de Leeuw IM, Taphoorn MJ, Aaronson NK (2011) Normative data for the EORTC QLQ-C30 and EORTC-sexuality items in the general Dutch population. Eur J Cancer 47(5):667675. https://doi.org/10.1016/j.ejca.2010.11.004

40. Chang EL, Wefel JS, Maor MH, Hassenbusch SJ III, Mahajan A, Lang FF, Woo SY, Mathews LA, Allen PK, Shiu AS, Meyers CA (2007) A pilot study of neurocognitive function in patients with one to three new brain metastases initially treated with stereotactic radiosurgery alone. Neurosurgery 60(2):277-283. https://doi. org/10.1227/01.neu.0000249272.64439.b1

41. Minniti G, Esposito V, Clarke E, Scaringi C, Bozzao A, Lanzetta G, De Sanctis V, Valeriani M, Osti M, Enrici RM (2013) Stereotactic radiosurgery in elderly patients with brain metastases. J Neurooncol 111(3):319-325. https://doi.org/10.1007/s1106 0-012-1016-Z

42. Meyers CA, Smith JA, Bezjak A, Mehta MP, Liebmann J, Illidge T, Kunkler I, Caudrelier JM, Eisenberg PD, Meerwaldt J, Siemers R, Carrie C, Gaspar LE, Curran W, Phan SC, Miller RA, Renschler MF (2004) Neurocognitive function and progression in patients with brain metastases treated with whole-brain radiation and motexafin gadolinium: results of a randomized phase III trial. J Clin Oncol 22(1):157-165. https://doi.org/10.1200/ jco.2004.05.128
43. Jak AJ, Bondi MW, Delano-Wood L, Wierenga C, Corey-Bloom J, Salmon DP, Delis DC (2009) Quantification of five neuropsychological approaches to defining mild cognitive impairment. Am J Geriatr Psychiatry 17(5):368-375. https://doi.org/10.1097/ JGP.0b013e31819431d5

44. Brown PD, Jaeckle K, Ballman KV et al (2016) Effect of radiosurgery alone vs radiosurgery with whole brain radiation therapy on cognitive function in patients with 1 to 3 brain metastases: a randomized clinical trial. JAMA 316(4):401-409. https://doi. org/10.1001/jama.2016.9839

45. Caissie A, Nguyen J, Chen E, Zhang L, Sahgal A, Clemons M, Kerba M, Arnalot PF, Danjoux C, Tsao M, Barnes E, Holden L, Danielson B, Chow E (2012) Quality of life in patients with brain metastases using the EORTC QLQ-BN20 + 2 and QLQ-C15PAL. Int J Radiat Oncol Biol Phys 83(4):1238-1245. https://doi. org/10.1016/j.ijrobp.2011.09.025

46. Steinmann D, Paelecke-Habermann Y, Geinitz H, Aschoff R, Bayerl A, Bölling T, Bosch E, Bruns F, Eichenseder-Seiss U, Gerstein J, Gharbi N, Hagg J, Hipp M, Kleff I, Müller A, Schäfer C, Schleicher U, Sehlen S, Theodorou M, Wypior H-J, Zehentmayr F, van Oorschot B, Vordermark D (2012) Prospective evaluation of quality of life effects in patients undergoing palliative radiotherapy for brain metastases. BMC Cancer 12(1):283. https://doi. org/10.1186/1471-2407-12-283

47. Reeve BB, Potosky AL, Smith AW, Han PK, Hays RD, Davis WW, Arora NK, Haffer SC, Clauser SB (2009) Impact of cancer on health-related quality of life of older Americans. J Natl Cancer Inst 101(12):860-868. https://doi.org/10.1093/jnci/djp123

48. Wilson IB, Cleary PD (1995) Linking clinical variables with health-related quality of life. A conceptual model of patient outcomes. JAMA 273(1):59-65

49. Caissie A, Culleton S, Nguyen J, Zhang L, Zeng L, Holden L, Dennis K, Chan E, Jon F, Tsao M, Danjoux C, Sahgal A, Barnes E, Koo K, Chow E (2011) What QLQ-C15-PAL symptoms matter most for overall quality of life in patients with advanced cancer? World J Oncol 2(4):166-174 